\title{
Characterisation of bacterial growth and antimicrobial susceptibility patterns in canine urinary tract infections
}

\author{
Ulrika Windahl1 ${ }^{*}$, Bodil Ström Holst ${ }^{2}$, Ann Nyman ${ }^{1}$, Ulrika Grönlund ${ }^{2}$ and Björn Bengtsson ${ }^{1}$
}

\begin{abstract}
Background: Bacterial urinary tract infection (UTI) is a common reason for antimicrobial therapy in dogs. A reported increase in multi-drug resistance in canine bacterial pathogens, including resistance to extendedspectrum cephalosporins (ESC) is of concern as antimicrobial resistance complicates therapy in dogs. In addition, it is a possible public health concern.

The objectives of this study were to investigate the relative prevalence of pathogens in urine samples from dogs with urinary tract infection sampled at referral hospitals, clinics and mixed veterinary practices and to investigate if this was influenced by sample material or by contamination of the culture. The second objective was to assess the susceptibility patterns to clinically relevant antimicrobials and to investigate if this was influenced by whether the samples originated from smaller clinics or from referral hospitals and to perform active screening for the presence of Enterobacteriaceae resistant to ESC.

Results: Escherichia coli was the most frequently isolated pathogen (68\%) followed by staphylococci (11\%). E. coli isolates were found significantly more often in pure culture than in contaminated samples. Staphylococcus pseudintermedius and Staphylococcus aureus isolates were significantly more prevalent in pre-incubated samples compared to samples submitted as non-incubated media.

Susceptibility to the majority of the tested first-line antimicrobials was common. Multiresistance was rare, and these isolates were all susceptible to at least one relevant antimicrobial. Isolates in samples from small animal clinics or mixed veterinary practices were less likely to be susceptible compared to isolates originating from referral animal hospitals. ESC-resistant Enterobacteriacae isolates were found in one per cent of the positive cultures. Bacteria with transferable ESC resistance were confirmed in one dog. The gene demonstrated was bla $a_{\mathrm{CM} 2}$.

Conclusions: Choice of sample material might influence the possibility of detecting Staphylococcus pseudintermedius and Staphylococcus aureus isolates in clinical cases of UTI in dogs. Based on the study results, use of first-line antimicrobials is a rational empirical antimicrobial therapy for the studied dog population.

E. coli was the most prevalent pathogen, but prevalence of infection with ESC resistant Enterobacteriaceae including E. coli was low, as such isolates were found in only one per cent of the positive cultures.
\end{abstract}

Keywords: Urinary tract, Bacterial infection, Dog, Antimicrobial resistance, Extended spectrum cephalosporins

\footnotetext{
* Correspondence: ulrika.windahl@sva.se

${ }^{1}$ Department of Animal Health and Antimicrobial Strategies, National

Veterinary Institute, SVA SE-751 89 Uppsala, Sweden

Full list of author information is available at the end of the article
} 


\section{Background}

Bacterial urinary tract infection (UTI) is a common clinical problem in dogs and among the most common reason for antimicrobial therapy, with approximately $14 \%$ of all dogs having at least one episode of UTI during their lifetime [1]. An increase in multi-drug resistance in canine bacterial pathogens, including resistance to extendedspectrum cephalosporins (ESC) associated with the production of extended-spectrum beta-lactamases (ESBL) or AmpC beta-lactamases, in urinary isolates has been reported [2-6]. Increasing antimicrobial resistance in canine bacterial pathogens is of concern as it complicates therapy in dogs. In addition, it is a public health concern when the pathogens are zoonotic, or the location of the resistance genes enables transfer between bacteria of animal and human origin [5,7].

Prudent use of antimicrobials is an important step in reducing the emergence of antimicrobial resistance. Microbiological culture combined with susceptibility testing is the cornerstone of UTI diagnosis and the best instrument for guiding treatment decisions in individual dogs $[8,9]$. However, empirical treatment is often necessary before the culture and susceptibility results are available. In the context of canine UTIs, prudent use thus includes considering likely pathogens and their susceptibility patterns when choosing empirical treatment [8].

The first objective of this study was to estimate the relative prevalence of uropathogens in dogs with urinary tract infections and to investigate if this was influenced by sample material or by contamination of the culture. The second objective was to assess the susceptibility patterns to clinically relevant antimicrobials and to investigate if this was influenced by whether the samples originated from smaller veterinary clinics or from referral hospitals and to perform active screening for the presence of Enterobacteriaceae resistant to ESC. The results were intended to aid in assessing culture results from urinary tract infections in dogs in clinical practice and to provide a basis for rational empirical antimicrobial therapy. Moreover, the results were to provide a basis for future monitoring of trends in antimicrobial resistance.

\section{Methods}

\section{Samples}

The urine samples were routine samples collected from dogs with clinical signs of urinary tract infection and submitted by the attending veterinarian to SVA (National Veterinary Institute, Sweden) for culture and susceptibility testing during a ten-month study period (March-December 2009).

\section{Culture}

The samples were processed on the day of arrival to SVA. The referred material (urine sent in a sterile container, bacterial swabs, representative colonies on dipslide, or agar plate bacterial cultures) were inoculated and spread onto horse blood agar (National Veterinary Institute, Uppsala, Sweden) and onto Cysteine Lactose Electrolyte Deficient agar (Oxoid Ltd, Merck KGaA). All inoculated agar plates were incubated at $37^{\circ} \mathrm{C}$ for 24 to $48 \mathrm{~h}$ until adequate growth was present. Bacterial identification was based on colony type and morphology, gram staining characteristics and standard biochemical tests [10-12]. In addition, material from each submitted sample $(0.1 \mathrm{~mL}$ of urine or, when the submitted sample consisted of preincubated cultures, the colony material collected by streaking across the agar using a calibrated loop), was spread onto MacConkey agar (National Veterinary Institute, Uppsala, Sweden) supplemented with cefotaxime $(1 \mathrm{mg} / \mathrm{L})$ (Sigma-Aldrich) with the objective to screen for Enterobacteriaceae resistant to ESC.

After incubation at $37^{\circ} \mathrm{C}$ for 24 to $48 \mathrm{~h}$ until adequate growth, colonies that based on type and morphology were identified as possible Escherichia coli, Klebsiella spp. or Enterobacter spp. were selected and spread on horseblood agar $(5 \% \mathrm{v} / \mathrm{v})$ and incubated overnight. To identify relevant isolates when growth on the selective media was rich, colonies were spread onto horse-blood agar with a cefotaxime disc $(30 \mu \mathrm{g}$, CTO166B Oxoid Ltd) on the agar surface. The final identification of up to eight representative isolates per agar plate was based on production of tryptophanase (indole) and ß-glucuronidase (p-nitrophenylß-D- glucopyranosiduronic acid, PGUA) and the analytical profile index API $20 \mathrm{E}^{\circledast}$ identification system (bioMérieux).

\section{Antimicrobial susceptibility}

Antimicrobial susceptibility was tested by determination of minimum inhibitory concentration (MIC) using broth microdilution following the standards of the Clinical and Laboratory Standards Institute [13] and using VetMIC panels (SVA, Uppsala, Sweden). Escherichia coli ATCC 25922 and Enterococcus faecalis ATCC 29212, Staphylococcus aureus ATCC 29213 and Pseudomonas aeruginosa ATCC 27853 were used for quality control. In addition, staphylococci were tested for beta-lactamase production by the "clover-leaf" method as described by Bryan and Godfrey [14]. Isolates of presumptive uropathogens were tested for susceptibility to antimicrobials relevant for the respective bacterial species [15]. Specifically, E. coli, Klebsiella spp. and $P$. mirabilis were tested for susceptibility to cefotaxime as an indicator of ESC-resistance, and S. pseudintermedius and S. aureus were tested for susceptibility to oxacillin as an indicator of methicillin resistance. Isolates were classified as susceptible to an antimicrobial according to MIC breakpoints for bacteria from animals issued by CLSI [16]. CLSI breakpoints for bacteria from humans were used for nitrofurantoin and cefotaxime as there are no interpretive criteria for bacteria from animals 
for these antimicrobials [17]. Only isolates of staphylococci not producing beta-lactamase were classified as susceptible to ampicillin and penicillin.

An isolate was classified as multiresistant (MDR) if it was intermediately susceptible or resistant to three or more antimicrobial classes according to CLSI breakpoints. For the classification of MDR in E. coli, Klebsiella spp. and $P$. mirabilis, ampicillin and amoxicillin-clavulanic acid were considered one antimicrobial class. For the classification of staphylococci, streptococci and enterococci, ampicillin, amoxicillin-clavulanic acid, cephalothin and penicillin were considered one antimicrobial class. Antimicrobials to which a bacterial species has inherently low susceptibility were not included in the classification of MDR. This applies to ampicillin and nitrofurantoin in Klebsiella spp., nitrofurantoin and tetracycline in $P$. mirabilis and to enrofloxacin and gentamicin in streptococci. Enterococci have constitutively low susceptibility to several of the antimicrobials studied, and only ampicillin, tetracycline, trimethoprim-sulphametoxazole and nitrofurantoin were considered in the evaluation of MDR in enterococci.

Isolates of E. coli, Klebsiella spp. and Enterobacter spp. recovered from the screening for ESC-resistance were tested for susceptibility to cefotaxime by broth microdilution as described above. Isolates with cefotaxime $\mathrm{MIC}>1 \mathrm{mg} / \mathrm{L}$ were further analysed for the production of ESBL or AmpC by the double disc diffusion test according to CLSI [13].

\section{Genotyping}

Presumptive methicillin resistant staphylococci, based on oxacillin MIC, were tested for presence of the mecA gene by PCR as described by Strommenger et al. [18]. To differentiate isolates of Enterobacteriaceae with chromosomal AmpC production from isolates carrying plasmidic AmpC, a multiplex PCR assay for the plasmid carrying the beta-lactamase families MOX, CIT, DHA, $\mathrm{ACC}, \mathrm{EBC}$ and FOX was used [19]. In isolates shown to carry plasmidic AmpC, the gene variants were determined by sequencing using in-house primers $\left(\mathrm{bla}_{\mathrm{cmy}-2}\right.$ 5' - AAATCGTTATGCTSCGCTCT and 5' - CATGG GATTTTCCTTGCTGT) and Big-Dye $^{\mathrm{Tm}} \mathrm{v} 1.1$.

\section{Statistical analyses}

The statistical analyses were performed using Stata Software (StataCorp. 2012; Stata Statistical Software: Release 11.2; College Station, TX, USA: StataCorpLP). Descriptive statistics were used to describe the uropathogens isolated in pure and contaminated culture, in different sample media (pre-incubated cultures or non-incubated samples), and from different submission categories. Univariable associations between findings of the isolated uropathogens and the three explanatory variables; submission category, sample media (whether the samples were sent in as pre-incubated cultures or not), and if the samples were in pure or contaminated cultures were investigated using Fisher's exact-test, the $\chi^{2}$-test and univariable logistic regression analysis. The same tests were used for investigation of aassociations between submission category and if samples were in pure or contaminated culture, as well as for associations between submission category and the use of different sample media. The same univariable tests were used to investigate if antimicrobial susceptibility in isolates varied by submission category. Moreover, for every uropathogen a multivariable logistic regression analysis was performed using a manual stepwise backward variable selection procedure in where the initial models included all three explanatory variables as main effects. Collinearity between the explanatory variables was assessed pair-wise by Spearman rank correlations. If there was proof of collinearity $(r \geq 0.70)$ the variable with lowest $P$-value in the univariable analysis was selected. All plausible two-way interactions between the significant main effects were tested. Variables with a significant association $(P<0.05)$ with the dependent variable were kept in the model. The model fit was evaluated with the Hosmer-Lemeshow goodness-of-fit test and by visual examination of diagnostic plots as outlined by Hosmer and Lemeshow [20]. For all the analyses performed, the level of statistical significance was set at $P \leq 0.05$.

\section{Ethics}

All samples were collected during routine diagnostics. The study was approved by the Swedish Board of Agriculture and the Ethical Committee on Animal Experiments in Uppsala.

\section{Results}

\section{Population characteristics}

Of the in total 1042 submitted samples, 469 (45\%) originated from four small animal referral hospitals that submitted 94-129 samples each. Approximately a quarter of the samples $(n=277 ; 27 \%)$ were referred by ten separate small animal clinics, each contributing 11-55 samples. The remaining 296 samples (28\%) were from 115 mixed veterinary practices, of which none submitted more than ten urinary samples. These three submission categories; small animal referral hospitals, small animal clinics and mixed veterinary practices were labelled A, B and C, respectively (Table 1).

\section{Characterisation of bacterial growth}

Of the submitted samples, 961 were found to be from individual dogs. A specific urinary pathogen was isolated in 623 (65\%) of these. Culture of 338 samples (35\%) yielded either no bacterial growth or only insignificant non-specific growth of contaminants, including 20 samples where more than one possible pathogen was found 
Table 1 Findings of uropathogens in submitted urinary samples presented by submission category, sample material and growth

\begin{tabular}{|c|c|c|c|c|c|c|c|}
\hline & \multicolumn{3}{|c|}{ Submission category } & \multicolumn{2}{|l|}{ Sample material } & \multicolumn{2}{|l|}{ Growth } \\
\hline & $\begin{array}{l}A \\
\%(n)\end{array}$ & $\begin{array}{l}B \\
\%(n)\end{array}$ & $\begin{array}{l}C \\
\%(n)\end{array}$ & $\begin{array}{l}\text { Pre-incubated } \\
\% \text { (n) }\end{array}$ & $\begin{array}{l}\text { Non-incubated } \\
\%(\mathrm{n})\end{array}$ & $\begin{array}{l}\text { Pure } \\
\%(n)\end{array}$ & $\begin{array}{l}\text { Conta-minated } \\
\%(n)\end{array}$ \\
\hline Positive cultures individual dogs $(n=623)$ & $45(284)$ & $25(154)$ & $30(185)$ & $68(423)$ & $32(200)$ & $60(375)$ & $40(248)$ \\
\hline Positive cultures repeated samples $(n=48$ ) & $52(25)$ & $33(16)$ & $13(7)$ & $83(40)$ & $17(8)$ & $58(28)$ & $42(20)$ \\
\hline Samples without significant growth $(n=371)$ & $43(160)$ & $29(107)$ & $28(104)$ & $26(95)$ & $74(276)$ & 0 & 0 \\
\hline
\end{tabular}

The relative prevalence (\%) is presented with the number of samples shown inside brackets.

together with growth of contaminants that prohibited further confirmation of the suspected findings (Table 1). Eighty-one of the submitted samples were found to be repeated samples from dogs already included in the study. Of these, 48 positive cultures were found to be repeated samples from 40 dogs, and 33 samples yielded no growth or only non-specific growth. The 48 repeated samples with positive cultures were evaluated separately.

Significantly more pre-incubated $(68 \%, n=423)$ than non-incubated samples $(32 \%, \mathrm{n}=200)$ yielded positive culture results $(P<0-001)$. Samples that were incubated prior to referral were six times more likely to yield positive growth.

Positive cultures from individual dogs

Seven different urinary pathogens were identified in the 623 positive cultures with a specific urinary pathogen. Escherichia coli was the most prevalent, being identified in $429(68.9 \%)$ of the samples, followed by $S$. pseudintermedius (9.6\%, $\mathrm{n}=60), P$. mirabilis $(8.8 \%, \mathrm{n}=55)$, beta haemolytic Streptococcus spp. (5.6\%, $\mathrm{n}=35)$, Enterococcus spp. (3.7\%,

Table 2 Relative prevalence of uropathogens in non-repeated urinary samples from individual dogs

\begin{tabular}{|c|c|c|c|c|c|c|c|}
\hline $\begin{array}{l}\text { Submission category A referral } \\
\text { hospitals } 45 \%,(n=284)\end{array}$ & E.coli & $\begin{array}{l}\text { S. pseudo- } \\
\text { intermedius }\end{array}$ & $\begin{array}{l}\text { Proteus } \\
\text { mirabilis }\end{array}$ & $\begin{array}{l}\beta \text {-haemolytic } \\
\text { Streptococcus spp. }\end{array}$ & S. aureus & $\begin{array}{l}\text { Enterococcus } \\
\text { spp. }\end{array}$ & $\begin{array}{l}\text { Klebsiella } \\
\text { spp. }\end{array}$ \\
\hline \multicolumn{8}{|l|}{ Pre-incubated $87 \%,(n=248)$} \\
\hline Pure growth, $(n=174)$ & $72(131)$ & $57(16)$ & $77(10)$ & $78(7)$ & $57(4)$ & $71(5)$ & $33(1)$ \\
\hline Contaminated growth, $(n=74)$ & $28(50)$ & $43(12)$ & $23(3)$ & $22(2)$ & $43(3)$ & $29(2)$ & $67(2)$ \\
\hline \multicolumn{8}{|l|}{ Non-incubated, $13 \%(n=36)$} \\
\hline Pure growth, $(n=22)$ & $74(17)$ & $50(2)$ & $25(1)$ & $50(2)$ & - & $0(0)$ & - \\
\hline Contaminated growth, $(n=14)$ & $26(6)$ & $50(2)$ & $75(3)$ & $50(2)$ & - & $100(1)$ & - \\
\hline $\begin{array}{l}\text { Submission category B small } \\
\text { animal clinics } 25 \%,(n=154)\end{array}$ & E.coli & $\begin{array}{l}\text { S. pseudo- } \\
\text { intermedius }\end{array}$ & $\begin{array}{l}\text { Proteus } \\
\text { mirabilis }\end{array}$ & $\begin{array}{l}\beta \text {-haemolytic } \\
\text { Streptococcus spp. }\end{array}$ & S. aureus & $\begin{array}{l}\text { Enterococcus } \\
\text { spp. }\end{array}$ & $\begin{array}{l}\text { Klebsiella } \\
\text { spp. }\end{array}$ \\
\hline \multicolumn{8}{|l|}{ Pre-incubated, 56\%, $(n=87)$} \\
\hline Pure growth, $(n=53)$ & $68(42)$ & $67(6)$ & $33(3)$ & $0(0)$ & $0(0)$ & $100(2)$ & $0(0)$ \\
\hline Contaminated growth, $(n=34)$ & $32(20)$ & $33(3)$ & $67(6)$ & $100(2)$ & $100(1)$ & $0(0)$ & $100(2)$ \\
\hline \multicolumn{8}{|l|}{ Non-incubated, 44\%, $(n=67)$} \\
\hline Pure growth, $(n=34)$ & $52(25)$ & $67(2)$ & $75(6)$ & $0(0)$ & - & $33(1)$ & - \\
\hline Contaminated growth, $(n=33)$ & $48(23)$ & $33(1)$ & $25(2)$ & $100(5)$ & - & $67(2)$ & - \\
\hline $\begin{array}{l}\text { Submission category C mixed } \\
\text { veterinary practices } 30 \%,(n=185)\end{array}$ & E.coli & $\begin{array}{l}\text { S. pseudo- } \\
\text { intermedius }\end{array}$ & $\begin{array}{l}\text { Proteus } \\
\text { mirabilis }\end{array}$ & $\begin{array}{l}\beta \text {-haemolytic } \\
\text { Streptococcus spp. }\end{array}$ & S. aureus & $\begin{array}{l}\text { Enterococcus } \\
\text { spp. }\end{array}$ & $\begin{array}{l}\text { Klebsiella } \\
\text { spp. }\end{array}$ \\
\hline \multicolumn{8}{|l|}{ Pre-incubated, $48 \%,(n=88)$} \\
\hline Pure growth, $(n=45)$ & $52(29)$ & $50(6)$ & $67(6)$ & $25(1)$ & $100(2)$ & $33(1)$ & $0(0)$ \\
\hline Contaminated growth, $(n=43)$ & $48(27)$ & $50(6)$ & $33(3)$ & $75(3)$ & $0(0)$ & $67(2)$ & $100(2)$ \\
\hline \multicolumn{8}{|l|}{ Non-incubated, $52 \%,(n=97)$} \\
\hline Pure growth, $(n=47)$ & $51(30)$ & $50(2)$ & $50(6)$ & $36(4)$ & - & $43(3)$ & $50(2)$ \\
\hline Contaminated growth, $(n=50)$ & $49(29)$ & $50(2)$ & $50(6)$ & $64(7)$ & - & $57(4)$ & $50(2)$ \\
\hline Total & $68(429)$ & $10(60)$ & $9(55)$ & $5(35)$ & $2(10)$ & $4(23)$ & $2(11)$ \\
\hline
\end{tabular}

The relative prevalence (\%) is presented by the three submission categories; small animal referral hospitals, small animal clinics and mixed veterinary practices are labelled A, B and C, respectively, as well as by submitted sample material and by pure- or contaminated growth. The number of samples is shown inside brackets. 
$\mathrm{n}=23)$, Klebsiella spp. $(1.8 \%, \mathrm{n}=11)$ and S. aureus $(1.6 \%$, $\mathrm{n}=10$ ) (Table 2).

Forty-six per cent $(n=284)$ of the 623 cultures with a specific urinary pathogen originated from submission category A, 25\% $(n=154)$ from category B and 30\% $(n=185)$ from category C. Approximately $68 \%(n=423)$ of the samples were submitted to the laboratory as pre-incubated cultures on dipslides (42\%) or agar plates (26\%). The 200 non-incubated samples were submitted in the form of urine collected in a sterile container $(19 \%)$ or as bacterial swabs dipped in urine (13\%). Submission category A sent in more samples using pre-incubated sample media than submission groups $\mathrm{B}$ and $\mathrm{C}(P<0.001$ and $P<0.001$, respectively).

Of the 623 samples, $60 \%(n=375)$ were in pure growth, and $40 \%(n=248)$ were in contaminated growth (Table 1$)$. Significantly more samples from submission category A were in pure culture compared to submission categories B $(P<0.01)$ and $C(P<0.001)$. Significantly more preincubated than non-incubated samples were in pure culture $(\mathrm{P}<0.01)$ compared to contaminated culture. No significant differences were observed between the pre-incubated or non-incubated samples and the pure or contaminated samples when submission category was considered (Table 2).

The results of the multivariable logistic regression analyses of associations between the bacterial findings and the explanatory variables (submission category, submitted sample media and whether the samples were contaminated) differed between the uropathogens. The only multivariable model where more than one explanatory variable was significantly associated with the analysed uropathogen was the model of association with findings of beta haemolytic Streptococcus spp. Hence, the results for all other uropathogens are from the univariable logistic regression analyses.

There was a higher probability of finding S. pseudintermedius in pre-incubated sample media $(\mathrm{n}=49)$ compared to non-incubated sample media $(\mathrm{OR}=2.2 ; \mathrm{P}=0.019 ; \mathrm{n}=$ $20)$. The use of pre-incubated sample media was associated with a lower probability of finding beta haemolytic Streptococcus spp. (OR $=0.4 ; P=0.004 ; \mathrm{n}=15)$ compared to non-incubated sample media $(\mathrm{n}=20)$. The ten $S$. aureus isolates were all found in pre-incubated samples. The probability of finding $E$. coli was lower $(\mathrm{OR}=0.6 ; P=$ $0.005)$ in contaminated cultures $(n=155)$ than in pure cultures $(\mathrm{n}=274)$, while the probability of finding beta haemolytic Streptococcus spp. $(\mathrm{OR}=2.1 ; P=0.04 ; \mathrm{n}=21)$ or Klebsiella spp. $(\mathrm{OR}=4.1 ; P=0.04 \mathrm{n}=8)$ was higher in contaminated cultures compared to pure cultures $(n=14$ and $n=3$, respectively).

\section{Positive cultures from repeated samples}

The same pathogen was isolated on both occasions in all 48 repeated sample occasions with positive culture results.
The bacteria isolated were E. coli $(81.2 \%, \mathrm{n}=39)$, S. pseudintermedius $(6.3 \%, \mathrm{n}=3)$, P. mirabilis $(6.3 \%, \mathrm{n}=3) \%$, Klebsiella spp. (4.2\%, $\mathrm{n}=2) \%)$, and Enterococcus spp. $(2.0 \%, \mathrm{n}=1)$.

All but four samples were submitted by the same veterinary practice, clinic or hospital that sampled the dog the first time. Approximately half of the samples (52\%, $\mathrm{n}=25$ ) originated from category $\mathrm{A}$, one third $(33 \%, \mathrm{n}=$ $16)$ were from category $B$ and $14 \%(n=7)$ were from category C. For all but two dogs, the submitted sample material did not differ between the sample occasions, and $83 \%(n=40)$ of the samples were submitted as preincubated cultures.

\section{Antimicrobial susceptibility patterns in positive cultures from individual dogs}

Of the gram-negative pathogens, E. coli had the overall highest percentage of susceptibility (Table 3). Most (79\%) $E$. coli isolates were susceptible to all the tested antimicrobials. Susceptibility to the individual antimicrobials varied between 87 and approximately 100\%, with reduced susceptibility to aminopenicillins (ampicillin and amoxicillinclavulanic acid) being the most common trait (Table 3). Seventeen E. coli isolates (4\%) were multiresistant (Table 4). Eleven of these isolates were susceptible both to first generation fluoroquinolones (enrofloxacin) and nitrofurantoin. The remaining six multiresistant isolates were susceptible to at least one antimicrobial, which was usually nitrofurantoin.

The majority (73 to 95\%) of Klebsiella spp. and $P$. mirabilis isolates were susceptible to amoxicillinclavulanic acid, gentamicin, enrofloxacin and trimethoprimsulfamethoxazole. Ninety-one per cent of $P$. mirabilis isolates were susceptible to ampicillin. Constitutive resistance was reflected in the low number of isolates being susceptible to nitrofurantoin in both species (27\% and 9\%, respectively), in susceptibility to tetracycline being observed in less than $6 \%$ of the $P$. mirabilis isolates, and by none of the Klebsiella spp. isolates being susceptible to ampicillin (Table 3). No Klebsiella spp. isolates were susceptible to ampicillin. Disregarding constitutive resistance, no Klebsiella spp. isolates were multiresistant, although one isolate was neither susceptible to gentamicin nor to trimethoprim-sulphametoxazole. Only one $P$. mirabilis isolate (2\%) was multiresistant when constitutive resistance to tetracycline and nitrofurantoin was disregarded. The isolate was not susceptible to ampicillin, gentamicin or trimethoprim-sulphametoxazole. A reduced susceptibility to cefotaxime, MIC $>1 \mathrm{mg} / \mathrm{L}$ was detected in one isolate each of E. coli and P. mirabilis. Both of these isolates produced AmpC beta-lactamase. Further testing for the genotype was not performed.

The screening for isolates with ESC-resistance by culture on cefotaxime supplemented media yielded growth 
Table 3 Antimicrobial susceptibility (\%) of $E$. coli, Klebsiella spp. and $P$. mirabilis in non-repeated samples

\begin{tabular}{|c|c|c|c|c|c|c|c|c|c|c|c|c|c|}
\hline \multirow[t]{2}{*}{ Antimicrobial } & \multirow{2}{*}{$\begin{array}{l}\text { Breakpoint } \\
\mathrm{S} \\
(\mathrm{mg} / \mathrm{L})\end{array}$} & \multicolumn{4}{|c|}{ Escherichia coli } & \multicolumn{4}{|c|}{ Klebsiella spp. } & \multicolumn{4}{|c|}{ Proteus mirabilis } \\
\hline & & $\begin{array}{l}\text { All } \\
(429)\end{array}$ & $\begin{array}{l}\text { A } \\
(204)\end{array}$ & $\begin{array}{l}\text { B } \\
(110)\end{array}$ & $\begin{array}{l}C \\
(115)\end{array}$ & $\begin{array}{l}\text { All } \\
\text { (11) }\end{array}$ & $\begin{array}{l}A \\
(3)\end{array}$ & $\begin{array}{l}\text { B } \\
(2)\end{array}$ & $\begin{array}{l}C \\
(69\end{array}$ & $\begin{array}{l}\text { All } \\
\text { (55) }\end{array}$ & $\begin{array}{l}A \\
(17)\end{array}$ & $\begin{array}{l}\text { B } \\
\text { (17) }\end{array}$ & $\begin{array}{l}C \\
\text { (21) }\end{array}$ \\
\hline Ampicillin & $\leq 8$ & 87.9 & 91.2 & 85.5 & 84.3 & 0.0 & 0.0 & 0.0 & 0.0 & 90.9 & 88.2 & 94.1 & 90.5 \\
\hline Amoxicillin/Clavulanic acid & $\leq 8$ & 87.2 & 89.7 & 85.5 & 84.3 & 72.7 & 66.7 & 100 & 66.7 & 94.5 & 100 & 94.1 & 90.5 \\
\hline Cefotaxime & $\leq 1$ & 99.8 & 99.5 & 100 & 100 & 100 & 100 & 100 & 100 & 98.2 & 100 & 94.1 & 100 \\
\hline Gentamicin & $\leq 2$ & 94.9 & 95.1 & 93.6 & 95.7 & 90.9 & 100 & 100 & 83.3 & 83.6 & 82.4 & 82.4 & 85.7 \\
\hline Enrofloxacin & $\leq 0.5$ & 97.9 & 98.5 & 95.5 & 99.1 & 90.9 & 100 & 100 & 83.3 & 96.4 & 100 & 88.2 & 100 \\
\hline Tetracycline & $\leq 4$ & 92.1 & 95.1 & 90.0 & 88.7 & 100 & 100 & 100 & 100 & 5.5 & 5.9 & 5.9 & 4.8 \\
\hline Trimethoprim/Sulphametoxazole & $\leq 2 / 38$ & 92.3 & 96.6 & 89.1 & 87.8 & 90.9 & 100 & 100 & 83.3 & 89.1 & 88.2 & 88.2 & 90.5 \\
\hline Nitrofurantoin & $\leq 32$ & 98.4 & 99.5 & 98.2 & 96.5 & 27.3 & 33.3 & 50.0 & 16.7 & 9.1 & 5.9 & 11.8 & 9.5 \\
\hline
\end{tabular}

Breakpoints for susceptibility (BP S) (mg/L) are indicated. The number of samples is shown inside brackets. The three submission categories; small animal referral hospitals, small animal clinics and mixed veterinary practices are labelled A, B and C, respectively.

of E. coli (three samples), Enterobacter cloacae and Enterobacter aerogenes (two samples each). All seven isolates had cefotaxime $\mathrm{MIC} \geq 2 \mathrm{mg} / \mathrm{L}$ and were confirmed as AmpC producers by phenotypic tests. A plasmidic AmpC gene was confirmed in only one isolate, which was an E. coli isolate carrying a gene of the CIT group that was confirmed as $b l a_{\text {cmy-2 }}$ by sequencing. This isolate was obtained from the same sample as the E. coli isolate described above with reduced susceptibility to cefotaxime found on non-selective culture.

Only $10 \%$ of S. pseudintermedius and S. aureus isolates were susceptible to penicillin and ampicillin; $90 \%$ were resistant by production of beta-lactamase. Susceptibility to other antimicrobials ranged from 87 to $100 \%$, with the exception of tetracycline, to which about $65 \%$ of the isolates were susceptible (Table 5). One S. pseudintermedius isolate had oxacillin MIC $>2 \mathrm{mg} / \mathrm{L}$ and was confirmed as a mecA carrier. None of the $S$. aureus isolates but six isolates of S. pseudintermedius (10\%) were multiresistant, including the methicillin resistant isolate (Table 6). Beta-haemolytic streptococci were uniformly susceptible to penicillin, amoxicillin-clavulanic acid, trimethoprim-sulphametoxazole and nitrofurantoin. The proportion of isolates susceptible to tetracycline or enrofloxacin was lower, $64 \%$ and $15 \%$, respectively (Table 5). No isolate was multiresistant. Enterococci were the least susceptible of the isolated pathogens if all tested antimicrobials are considered (Table 5). However, susceptibility to ampicillin, amoxicillin-clavulanic acid, trimethoprim-sulphametoxazole and nitrofurantoin was high, with more than $80 \%$ of all the isolates being susceptible. Two isolates (9\%) were resistant to three or more of these antimicrobials (Table 5).

Comparison of susceptibility patterns between the three submission categories showed that the probability of finding trimethoprim-sulphametoxazole resistant $E$. coli was higher for submission categories $\mathrm{B}$ and $\mathrm{C}$ compared to submission group $\mathrm{A}(\mathrm{OR}=3.4 ; P=0.01$ and $\mathrm{OR}=3.9 ; P=$ 0.004 , respectively). The probability of finding tetracycline resistant $E$. coli was higher $(\mathrm{OR}=2.5 ; P=0.04)$ for submission category $\mathrm{C}$ than for submission category A. Escherichia coli from submission category $\mathrm{C}$ were more likely to be multiresistant than isolates from category A $(\mathrm{OR}=2.7 ; P=$ 0.02 ). There was a trend for isolates from category $B$ to be multiresistant to a greater extent than isolates from category $\mathrm{A}$, but the difference was not significant $(\mathrm{OR}=2.4$; $\mathrm{P}=0.052$ ). There were no associations between submission category and antimicrobial susceptibility of $P$. mirabilis or beta-haemolytic streptococci, and the small number of resistant isolates precluded a statistical assessment of such associations for S. pseudintermedius, S. aureus, Klebsiella spp. or Enterococcus spp.

\section{Antimicrobial susceptibility patterns in positive cultures from repeated samples}

Eighty-three per cent $(\mathrm{n}=32)$ of the $39 E$. coli isolates in cultures of the repeated samples were susceptible to all

Table 4 Resistance phenotypes of the 17 multidrugresistant $E$. coli isolates

\begin{tabular}{lllllll}
\hline Number of isolates & Ampicillin & Gentamicin & Enrofloxacin & Tetracycline & Trimethoprim/Sulphametoxazole & Nitrofurantoin \\
\hline 3 & R & R & R & R & R \\
1 & R & R & R & R & & R \\
1 & R & & & $\mathbf{R}$ & $\mathbf{R}$ & $\mathbf{R}$ \\
11 & $\mathbf{R}$ & & $\mathbf{R}$ & \\
1 & $\mathbf{R}$ & & $\mathbf{R}$ & $\mathbf{R}$ & \\
\hline
\end{tabular}

The letter " $\mathrm{R}$ " in bold indicates resistance. 
Table 5 Antimicrobial susceptibility (\%) of S. pseudintermedius, S. aureus, beta haemolytic streptococci and enterococci in non-repeated samples

\begin{tabular}{|c|c|c|c|c|c|c|c|c|}
\hline \multirow[t]{3}{*}{ Antimicrobial } & \multirow{2}{*}{\multicolumn{2}{|c|}{$\begin{array}{l}\text { Staphylococcus pseudintermedius } \\
(\mathrm{n}=60)\end{array}$}} & \multirow{2}{*}{\multicolumn{2}{|c|}{$\begin{array}{l}\text { Staphylococcus aureus } \\
(\mathrm{n}=10)\end{array}$}} & \multirow{2}{*}{\multicolumn{2}{|c|}{$\frac{\text { Beta-hemolytic streptococci }}{(n=33)}$}} & \multirow{2}{*}{\multicolumn{2}{|c|}{$\frac{\text { Enterococci }}{(\mathrm{n}=55)}$}} \\
\hline & & & & & & & & \\
\hline & BP S & $\% \mathrm{~S}$ & BP S & $\% \mathrm{~S}$ & BP S & $\% \mathrm{~S}$ & BP S & $\% \mathrm{~S}$ \\
\hline Penicillin & $\beta$-lact ${ }^{a}$ & 10.0 & $\beta$-lact & 30.0 & $\leq 0.12$ & 100 & $\leq 8$ & NR \\
\hline Ampicillin & $\beta$-lact & 10.0 & $\beta$-lact & 30.0 & $\leq 0.25$ & NR & $\leq 8$ & 87.0 \\
\hline Amoxicillin/Clavulanic acid & $\leq 8$ & 96.7 & $\leq 8$ & 100 & $\leq 8$ & 100 & $\leq 8$ & 82.6 \\
\hline Cephalothin & $\leq 2$ & 98.3 & $\leq 2$ & 100 & $\leq 2$ & 100 & $\leq 2$ & 13.0 \\
\hline Oxacillin & $\leq 0.25$ & $N R^{b}$ & $\leq 2$ & 100 & - & - & - & - \\
\hline Gentamicin & $\leq 2$ & 98.3 & $\leq 2$ & 100 & $\leq 2$ & 0.0 & $\leq 2$ & 30.4 \\
\hline Erythromycin & $\leq 0.5$ & 86.7 & $\leq 0.5$ & 100 & $\leq 0.25$ & NR & $\leq 0.5$ & 34.8 \\
\hline Enrofloxacin & $\leq 0.5$ & 98.3 & $\leq 0.5$ & 100 & $\leq 0.5$ & 15.2 & $\leq 0.5$ & 47.8 \\
\hline Tetracycline & $\leq 4$ & 66.7 & $\leq 4$ & 90.0 & $\leq 2$ & 63.6 & $\leq 4$ & 65.2 \\
\hline Trimethoprim/Sulphametoxazole & $\leq 2 / 38$ & 95.0 & $\leq 2 / 38$ & 100 & $\leq 2 / 38$ & 100 & $\leq 2 / 38$ & 87.0 \\
\hline Nitrofurantoin & $\leq 32$ & 100 & $\leq 32$ & 100 & $\leq 32$ & 100 & $\leq 32$ & 82.6 \\
\hline
\end{tabular}

Breakpoints for susceptibility (BP S) (mg/L) are indicated. The number of samples is shown inside brackets. Results from the susceptibility testing of one beta-haemolytic streptococcus isolate were lost and are not presented.

${ }^{a} \beta$-lact $=$ beta-lactamase production

${ }^{\mathrm{b}} \mathrm{NR}=$ not relevant since the $\mathrm{BP}$ is outside of the range of concentrations tested

the tested antimicrobials. In six of the seven cultures yielding $E$. coli isolates with resistance traits, the isolates were less susceptible than on the first sample occasion. Four isolates were multiresistant $(10 \%$ of the 39 E. coli isolates). Multiresistance was already present in the first isolates from the three dogs involved, but the isolates from the repeated samples had additional resistance to trimethoprim-sulphametoxazole. No Enterobacteriaceae resistant to ESC were isolated.

In eight of the nine dogs where bacteria other than $E$. coli were found, all isolates were susceptible to all antimicrobials tested on all sample occasions. In one dog, $S$. pseudintermedius susceptible to penicillin was isolated from the first and penicillin resistant S. pseudintermedius from the second sample occasion.

\section{Discussion}

The seven urinary pathogens isolated in this study are the bacterial pathogens most frequently associated with UTI in dogs [21-23]. In accordance with previous reports, E. coli was the most frequently cultured pathogen, followed by staphylococci, with S. pseudintermedius being more prevalent than S. aureus [2,21,24-27].

To avoid false-positive and false-negative results immediate culture after collection of a urine specimen is recommended. If this is not possible, the samples should ideally be refrigerated within 1 or 2 hours of collection $[27,28]$. In a practice setting urine is however often referred to an external laboratory for confirmation and identification of specific bacterial organisms [27,29]. Furthermore, it is not uncommon for both cystocentesis and second-best options in trying to avoid bacterial contamination of the sample, like catheterization or securing a midstream sample, to be unrealistic alternatives when colleting the sample due to either cost or practical problems in handling of the individual dog. The possible influence on the results of collection method and handling of the samples in the present study could not be fully evaluated as the collection methods were unknown, but prevalence of growth of the individual bacterial species was compared between the two categories pure and contaminated cultures. As previously reported, E. coli

Table 6 Resistance phenotypes of the six multidrugresistant S. pseudintermedius isolates

\begin{tabular}{|c|c|c|c|c|c|c|c|}
\hline $\begin{array}{l}\text { Number of } \\
\text { isolates }\end{array}$ & $\begin{array}{l}\text { Penicillin and } \\
\text { Aminopenicillins }\end{array}$ & Cephalotin & $\begin{array}{l}\text { Genta- } \\
\text { micin }\end{array}$ & $\begin{array}{l}\text { Erythro- } \\
\text { mycin }\end{array}$ & $\begin{array}{l}\text { Enro- } \\
\text { floxacin }\end{array}$ & $\begin{array}{l}\text { Tetra- } \\
\text { cycline }\end{array}$ & $\begin{array}{l}\text { Trimethoprim/ } \\
\text { Sulphametoxazole }\end{array}$ \\
\hline 2 & $\mathbf{R}$ & & S & $\mathbf{R}$ & S & $\mathbf{R}$ & $S$ \\
\hline 1 & $\mathbf{R}$ & & S & S & S & $\mathbf{R}$ & $\mathbf{R}$ \\
\hline 1 & $\mathbf{R}$ & & S & $\mathbf{R}$ & S & $\mathbf{R}$ & S \\
\hline 1 & $\mathbf{R}$ & & S & $\mathbf{R}$ & S & $\mathbf{R}$ & $\mathbf{R}$ \\
\hline $1^{a}$ & $R$ & $\mathbf{R}$ & $\mathbf{R}$ & $R$ & $\mathbf{R}$ & S & $R$ \\
\hline
\end{tabular}

The letter " $\mathrm{R}$ " in bold indicates resistance.

${ }^{a}$ mecA carrier. 
was found significantly more often in pure culture [30]. This indicates that the relatively high prevalence of $E$. coli in the material was not due to misinterpretation of faecal or genital contamination of samples.

The finding that samples submitted to the laboratory as pre-incubated agar plates or dipslide cultures yielded significantly more positive culture results than non-incubated urinary samples might be explained by attending veterinarians choosing not to submit agar-plates until growth of suspected pathogens is evident. Choice of material was not shown to be a major factor influencing the relative prevalence of bacterial species among the positive cultures, with the exception of staphylococci, which were found more often in pre-incubated sample media. Ling et al. [24] reported that Proteus spp. were isolated more frequently from urine specimens collected by catheterization or midstream catch than by cystocentesis, but to what extent the prevalence of various bacterial agents is influenced by sample technique and sample material is otherwise not well described. Further studies specifically designed to compare sample methods and sample materials are warranted.

In the present study, there was a possibility of more than one pathogen causing the UTI in two per cent of all the positive samples. This is in accordance with previous studies showing that more than $70 \%$ of UTIs in dogs are caused by a single pathogen $[8,24,29]$. None of the samples with multiple pathogens originated from the 45 dogs that were sampled repeatedly. This is in contrast to previous studies, where an association between a higher prevalence of multiple organisms and recurrent and persistent UTIs has been reported [21,31].

Antimicrobial susceptibility of $E$. coli from UTIs in dogs in Sweden has previously been reported from samples collected in 1991-92 and in 2002-03 [32]. If our data are reevaluated by the cut-off values used by Hagman \& Greko, the proportions of susceptible isolates in the two studies are similar [32]. Resistance in E. coli collected from UTIs in dogs in Sweden is apparently stable or improving, which is supported by national surveillance data showing that susceptibility to relevant antimicrobials has remained stable for the last two decades [33]. The situation is favourable in comparison to studies from other countries, where the proportion of susceptible $E$. coli is smaller $[30,34,35]$.

Susceptibility among Klebsiella spp. or Proteus mirabilis was high compared to previously reported data [34]. There were several appropriate first line antimicrobials available for treatment in the approximately ten per cent of UTIs caused by either of these two species. The constitutive resistance to nitrofurantoin in both species, to ampicillin and amoxicillin in Klebsiella spp. and to tetracycline in Proteus mirabilis is reflected in this study as well as in previous reports $[34,36]$.
Among the gram-positive isolates, susceptibility to penicillin and aminopenicillins was uncommon in staphylococci, while all streptococci were susceptible to these antimicrobials. In staphylococci, the second most common cause of UTI, susceptibility to other antimicrobials was high, ranging between 67 and 100\%, including $97 \%$ of the isolates being susceptible to amoxicillin-clavulanic acid. Our findings agree with previous reports $[26,34]$ and with data regarding the susceptibility of staphylococci and streptococci from dogs in Sweden reported in the monitoring program SWEDRES-SVARM [33]. The inherently low susceptibility of streptococci and enterococci to enrofloxacin that was demonstrated in this study has also been observed by others $[34,36]$. Several relevant treatment options were thus available when the UTI was caused by a gram-positive pathogen, including the $4 \%$ of UTIs caused by enterococci, which was the pathogen with the overall least favourable susceptibility pattern.

Many previous reports on growth of pathogens and antimicrobial susceptibility patterns in urinary tract infections in dogs are based on samples collected at referral animal hospitals based at universities in various countries. The samples included in the present study were from a wide range of veterinary practices with a geographical spread over the country and with both primary care facilities and referral animal hospitals represented, making the material representative of the actual population in the country. Interestingly, the probability of finding less susceptible isolates in our study was significantly higher in samples originating from small animal clinics or mixed veterinary practices than in samples from referral animal hospitals. The only exception to this was amoxicillin-clavulanic resistance in the limited number of Enterococcus spp. isolates. It has previously been stated that, as referral hospitals are more likely to have a higher caseload of complicated and recurrent cases, less susceptible isolates should be expected in samples originating from referral animal hospitals compared to smaller clinics $[24,25,32]$.

In accordance with previous studies, E. coli was the most common pathogen in the repeated samples $[8,21,22]$. The national guidelines states that culture and antimicrobial susceptibility testing always is to be performed when UTI is suspected in a dog, the only possible exception being uncomplicated first-time UTIs in young bitches (http:// www.smadjurssektionen.se/start/policys-och-guidelines). It is still possible that more dogs had been diagnosed with UTI previously, as other veterinary care facilities in the country do not routinely submit their samples for cultures to SVA. However, the low percentage of recurrent or persistent UTIs correlates with previous reports that concluded that the majority of UTIs in dogs are uncomplicated and occur as single episodes $[8,21,22]$. 
Multiresistance in E. coli isolates was twice as common in the repeatedly sampled 40 dogs compared to the dogs that were only sampled once. These findings support the need for culture and susceptibility testing and the need for investigating the possible underlying causes in dogs with recurrent or persistent UTI. However, to presume that the cause of a recurrent or persistent UTI is a resistant uropathogen needing combination therapy with broad-spectrum antimicrobials would be incorrect in more than $80 \%$ of the cases in the present study.

Phenotypic resistance to ESC in Enterobacteriaceae was rare. A similarly low ESC resistance in E. coli from dogs in Sweden was reported during $2010-2012$ in SVARM, where approximately $1 \%$ of $E$. coli from UTIs in dogs had reduced susceptibility to cefotaxime (MIC > $1 \mathrm{mg} / \mathrm{L}$ ) [33]. Higher prevalence of ESC resistant E. coli from various infections sites in dogs has been reported from other countries $[4,34,37]$ and transmissible genes coding ESC resistance known to be common in isolates from humans have been found in bacteria isolated from pet animals $[4,38,39]$. In the present study, the only transmissible gene demonstrated was $b l a_{\mathrm{CMY} 2}$, which in a contemporary study was found in only a small proportion of ESC resistant E. coli from humans in Sweden [33]. This scenario might change if ESC resistance becomes common in dogs, and vigilance towards ESC resistance in animal healthcare is warranted.

\section{Conclusions}

E. coli was the most frequent pathogen identified in the study followed by staphylococci. E. coli was found more often in pure culture than in contaminated samples. Choice of sample material might influence the possibility of detecting Staphylococcus pseudintermedius and Staphylococcus aureus isolates in clinical cases of UTI in dogs, as S. pseudintermedius and $S$. aureus were more prevalent in samples submitted to the laboratory as pre-incubated sample media compared to samples submitted as non-incubated media.

The results of the susceptibility testing were favourable and use of only first-line antimicrobials is based on the study results a rational empirical antimicrobial therapy for the studied dog population. Disregarding constitutive resistance, susceptibility to the majority of the tested first line antimicrobials was common. Multiresistance was rare, and such isolates were all susceptible to at least one antimicrobial relevant for the species and for the treatment of UTI. Isolates were less susceptible in samples originating from small animal clinics or mixed veterinary practices compared to the samples from referral animal hospitals.

Phenotypic resistance to ESC in Enterobacteriaceae was found in one per cent of all positive cultures. Bacteria with transferable ESC resistance were confirmed in only one dog. The gene demonstrated was bla $a_{\mathrm{CMY} 2}$.
Competing interests

The authors declare that they have no competing interests.

\section{Authors' contributions}

UW designed and coordinated the study and drafted the manuscript. AN performed the statistical analyses. BB and UG supervised the genotyping antimicrobial resistance. $\mathrm{AN}, \mathrm{BB}$ and $\mathrm{BSH}$ participated in drafting the manuscript. All authors commented on the manuscript and approved the final version.

\section{Acknowledgments}

Financial support was received from the Research Fund of the National Veterinary Institute, Uppsala, Sweden, where the authors are, or have been employed.

\section{Author details}

'Department of Animal Health and Antimicrobial Strategies, National Veterinary Institute, SVA SE-751 89 Uppsala, Sweden. ${ }^{2}$ Department of Clinical Sciences, Swedish University of Agricultural Sciences, SE-75007 Uppsala, Sweden.

Received: 31 March 2014 Accepted: 10 September 2014

Published online: 24 September 2014

\section{References}

1. Ling GV: Therapeutic strategies involving antimicrobial treatment of the canine urinary tract. J Am Vet Med Assoc 1984, 185(10):1162-1164.

2. Prescott JF, Hanna WJ, Reid-Smith R, Drost K: Antimicrobial drug use and resistance in dogs. Can Vet J 2002, 43(2):107-116.

3. Ewers C, Bethe A, Wieler LH, Guenther S, Stamm I, Kopp PA, Grobbel M: Companion animals: a relevant source of extended-spectrum beta-lactamase-producing fluoroquinolone-resistant Citrobacter freundii. Int J Antimicrob Agents 2011, 37(1):86-87.

4. Dierikx CM, van Duijkeren E, Schoormans AH, van Essen-Zandbergen A, Veldman K, Kant A, Huijsdens XW, van der Zwaluw K, Wagenaar JA, Mevius DJ: Occurrence and characteristics of extended-spectrum-beta-lactamase- and AmpC-producing clinical isolates derived from companion animals and horses. J Antimicrob Chemother 2012, 67(6):1368-1374.

5. Ewers C, Grobbel M, Bethe A, Wieler LH, Guenther S: Extended-spectrum beta-lactamases-producing gram-negative bacteria in companion animals: action is clearly warranted! Berl Munch Tierarztl Wochenschr 2011, 124(3-4):94-101

6. Weese JS, Blondeau JM, Boothe D, Breitschwerdt EB, Guardabassi L, Hillier A, Lloyd DH, Papich MG, Rankin SC, Turnidge JD, Sykes JE: Antimicrobial use guidelines for treatment of urinary tract disease in dogs and cats: antimicrobial guidelines working group of the international society for companion animal infectious diseases. Vet Med Int 2011, 2011:263768.

7. Guardabassi L, Schwarz S, Lloyd DH: Pet animals as reservoirs of antimicrobial-resistant bacteria. J Antimicrob Chemother 2004, 54(2):321-332.

8. Ball KR, Rubin JE, Chirino-Trejo M, Dowling PM: Antimicrobial resistance and prevalence of canine uropathogens at the Western College of Veterinary Medicine Veterinary Teaching Hospital, 2002-2007. Can Vet $J$ 2008, 49(10):985-990.

9. Bartges JW: Diagnosis of urinary tract infections. Vet Clin North Am Small Anim Pract 2004, 34(4):923-933.

10. Quinn PJCMJ, Markey BK, Carter GR: Clinical veterinary microbiology. Spain: Wolfe Publishing; 1994.

11. Carter GRCJR: Diagnostic Procedures in Veterinary bacteriology and Mycology, Fifth edn. Academic Press London/Sandiego; 1990.

12. Ling GV, Biberstein EL, Hirsh DC: Bacterial pathogens associated with urinary tract infections. Vet Clin North Am Small Anim Pract 1980, 9(4):617-630.

13. CLSI: Performance standards for Antimicrobial Disc and Dilution Susceptibility Tests for Bacteria Isolated from Animals; Approved Standard-Third Edition. CLSI document M31-A3. Wayne Pennsylvania, USA. 2008.

14. Bryan LE, Godfrey AJ: Beta-Lactam Antibiotics: Mode of action and bacterial resistance. In Antibiotics in Laboratory Medicine. Edited by Lorian V. Baltimore, USA: William \& Wilkins; 1991:648. 
15. Sykes JE: Antimicrobial Drug Use in Dogs and Cats. In Antimicrobial Therapy in Veterinary Medicine. 5th edition. Edited by Giguère SPJ, Dowling PM. Hoboken, NJ: John Wiley \& Sons, Inc; 2013

16. CLSI: Performance Standards for Antimicrobial Disk and Dilution Susceptibility Tests for Bacteria Isolated From Animals; Second Informational Supplement- CLSI document VET01-s2. Wayne, PA: Clinical and Laboratory Standards Institute; 2013.

17. CLSI: Performance Standards for Antimicrobial Susceptibility Testing; Twenty-Second Informational Supplement. CLSI document M100-S22. Wayne, PA: Clinical and Laboratory Standards Insitute; 2012.

18. Strommenger B, Kettlitz C, Werner G, Witte W: Multiplex PCR assay for simultaneous detection of nine clinically relevant antibiotic resistance genes in Staphylococcus aureus. J Clin Microbiol 2003, 41(9):4089-4094.

19. Perez-Perez FJ, Hanson ND: Detection of plasmid-mediated AmpC beta-lactamase genes in clinical isolates by using multiplex PCR. J Clin Microbiol 2002, 40(6):2153-2162.

20. Hosmer DW, Lemeshow S: Applied Logistic Regression. 2nd edition. New York: John Wiely \& Sons, Inc; 2000.

21. Norris CR, Williams BJ, Ling GV, Franti CE, Johnson Ruby AL: Recurrent and persistent urinary tract infections in dogs: 383 cases (1969-1995). J Am Anim Hosp Assoc 2000, 36(6):484-492.

22. Seguin MA, Vaden SL, Altier C, Stone E, Levine JF: Persistent urinary tract infections and reinfections in 100 dogs (1989-1999). J Vet Intern Med 2003, 17(5):622-631.

23. Thompson MF, Litster AL, Platell JL, Trott DJ: Canine bacterial urinary tract infections: new developments in old pathogens. Vet J 2011, 190(1):22-27.

24. Ling GV, Norris CR, Franti CE, Eisele PH, Johnson DL, Ruby AL, Jang SS: Interrelations of organism prevalence, specimen collection method, and host age, sex, and breed among 8,354 canine urinary tract infections (1969-1995). J Vet Intern Med 2001, 15(4):341-347.

25. Ogeer-Gyles J, Mathews K, Weese JS, Prescott JF, Boerlin P: Evaluation of catheter-associated urinary tract infections and multi-drug-resistant Escherichia coli isolates from the urine of dogs with indwelling urinary catheters. J Am Vet Med Assoc 2006, 229(10):1584-1590.

26. Penna B, Varges $R$, Martins R, Martins G, Lilenbaum W: In vitro antimicrobial resistance of staphylococci isolated from canine urinary tract infection. Can Vet J 2010, 51(7):738-742.

27. Rowlands M, Blackwood L, Mas A, Cripps P, Crompton C, Burrow R: The effect of boric acid on bacterial culture of canine and feline urine. J Small Anim Pract 2011, 52(10):510-514.

28. Lulich JP, Osborne CA: Urine culture as a test for cure: why, when, and how? Vet Clin North Am Small Anim Pract 2004, 34(4):1027-1041.

29. Tivapasi MT, Hodges J, Byrne BA, Christopher MM: Diagnostic utility and cost-effectiveness of reflex bacterial culture for the detection of urinary tract infection in dogs with low urine specific gravity. Vet Clin Pathol 2009, 38(3):337-342.

30. Oluoch AO, Kim CH, Weisiger RM, Koo HY, Siegel AM, Campbell KL, Burke TJ, McKiernan BC, Kakoma I: Nonenteric Escherichia coli isolates from dogs: 674 cases (1990-1998). J Am Vet Med Assoc 2001, 218(3):381-384

31. Stiffler KS, Stevenson MA, Sanchez S, Barsanti JA, Hofmeister E, Budsberg SC: Prevalence and characterization of urinary tract infections in dogs with surgically treated type 1 thoracolumbar intervertebral disc extrusion. Vet Surg 2006, 35(4):330-336.

32. Hagman R, Greko C: Antimicrobial resistance in Escherichia coli isolated from bitches with pyometra and from urine samples from other dogs. Vet Rec 2005, 157(7):193-196.

33. SWEDRES-SVARM: Use of antimicrobials and occurrence of antimicrobial resistance in Sweden. Solna/Uppsala ISSN 1650-6332. 2012.

34. Pedersen $K$, Jensen $H$, Finster $K$, Jensen VF, Heuer OE: Occurrence of antimicrobial resistance in bacteria from diagnostic samples from dogs. J Antimicrob Chemother 2007, 60(4):775-781.

35. Harada K, Niina A, Nakai Y, Kataoka Y, Takahashi T: Prevalence of antimicrobial resistance in relation to virulence genes and phylogenetic origins among urogenital Escherichia coli isolates from dogs and cats in Japan. Am J Vet Res 2012, 73(3):409-417.

36. Cohn LA, Gary AT, Fales WH, Madsen RW: Trends in fluoroquinolone resistance of bacteria isolated from canine urinary tracts. $J$ Vet Diagn Invest 2003, 15(4):338-343.

37. Shaheen BW, Boothe DM, Oyarzabal OA, Smaha T: Antimicrobial resistance profiles and clonal relatedness of canine and feline Escherichia coli pathogens expressing multidrug resistance in the United States. J Vet Intern Med 2010, 24(2):323-330.

38. O'Keefe A, Hutton TA, Schifferli DM, Rankin SC: First detection of CTX-M and SHV extended-spectrum beta-lactamases in Escherichia coli urinary tract isolates from dogs and cats in the United States. Antimicrob Agents Chemother 2010, 54(8):3489-3492.

39. Sun Y, Zeng Z, Chen S, Ma J, He L, Liu Y, Deng Y, Lei T, Zhao J, Liu JH: High prevalence of bla (CTX-M) extended-spectrum beta-lactamase genes in Escherichia coli isolates from pets and emergence of CTX-M-64 in China. Clin Microbiol Infect 2010, 16(9):1475-1481.

doi:10.1186/s12917-014-0217-4

Cite this article as: Windahl et al:: Characterisation of bacterial growth and antimicrobial susceptibility patterns in canine urinary tract infections. BMC Veterinary Research 2014 10:217.

\section{Submit your next manuscript to BioMed Central and take full advantage of:}

- Convenient online submission

- Thorough peer review

- No space constraints or color figure charges

- Immediate publication on acceptance

- Inclusion in PubMed, CAS, Scopus and Google Scholar

- Research which is freely available for redistribution 